\title{
BMJ Open Mental health in the UK during the COVID-19 pandemic: cross-sectional analyses from a community cohort study
}

\author{
Ru Jia, ${ }^{1}$ Kieran Ayling, ${ }^{1}$ Trudie Chalder, ${ }^{2}$ Adam Massey, ${ }^{1}$ Elizabeth Broadbent (D) , ${ }^{3}$ \\ Carol Coupland, ${ }^{1}$ Kavita Vedhara (i) ${ }^{1}$
}

To cite: Jia R, Ayling K, Chalder T, et al. Mental health in the UK during the COVID-19 pandemic: cross-sectional analyses from a community cohort study. BMJ Open 2020;10:e040620. doi:10.1136/ bmjopen-2020-040620

- Prepublication history for this paper is available online. To view these files, please visit the journal online (http://dx.doi. org/10.1136/bmjopen-2020040620).

Received 18 May 2020 Revised 20 August 2020 Accepted 25 August 2020

Check for updates

(c) Author(s) (or their employer(s)) 2020. Re-use permitted under CC BY-NC. No commercial re-use. See rights and permissions. Published by BMJ.

${ }^{1}$ Division of Primary Care, University of Nottingham, Nottingham, UK

${ }^{2}$ Psychological Medicine, King's College London, London, UK

${ }^{3}$ Faculty of Medical and Health Sciences, The University of Auckland, Auckland, New Zealand

Correspondence to Dr Kavita Vedhara; kavita.vedhara@nottingham. ac.uk

\section{ABSTRACT}

Objectives Previous pandemics have resulted in significant consequences for mental health. Here, we report the mental health sequelae of the COVID-19 pandemic in a UK cohort and examine modifiable and non-modifiable explanatory factors associated with mental health outcomes. We focus on the first wave of data collection, which examined short-term consequences for mental health, as reported during the first 4-6 weeks of social distancing measures being introduced.

Design Cross-sectional online survey.

Setting Community cohort study.

Participants $\mathrm{N}=3097$ adults aged $\geq 18$ years were recruited through a mainstream and social media campaign between 3 April 2020 and 30 April 2020. The cohort was predominantly female $(\mathrm{n}=2618)$; mean age 44 years; $10 \%(n=296)$ from minority ethnic groups; $50 \%$ $(n=1559)$ described themselves as key workers and $20 \%$ $(n=649)$ identified as having clinical risk factors putting them at increased risk of COVID-19.

Main outcome measures Depression, anxiety and stress scores.

Results Mean scores for depression $(\bar{x}=7.69, \mathrm{SD}=6.0)$, stress $(\bar{x}=6.48, \mathrm{SD}=3.3)$ and anxiety $(\bar{x}=6.48, \mathrm{SD}=3.3)$ significantly exceeded population norms (all $p<0.0001$ ). Analysis of non-modifiable factors hypothesised to be associated with mental health outcomes indicated that being younger, female and in a recognised COVID-19 risk group were associated with increased stress, anxiety and depression, with the final multivariable models accounting for $7 \%-14 \%$ of variance. When adding modifiable factors, significant independent effects emerged for positive mood, perceived loneliness and worry about getting COVID-19 for all outcomes, with the final multivariable models accounting for $54 \%-57 \%$ of total variance.

Conclusions Increased psychological morbidity was evident in this UK sample and found to be more common in younger people, women and in individuals who identified as being in recognised COVID-19 risk groups. Public health and mental health interventions able to ameliorate perceptions of risk of COVID-19, worry about COVID-19 loneliness and boost positive mood may be effective.

\section{INTRODUCTION}

The COVID-19 pandemic has resulted in unprecedented disruption to the fabric of

\section{Strength and limitations of this study}

To our knowledge, this paper provides the first empirical evidence from a large cohort on the mental health impact of the COVID-19 pandemic on people in the UK.

- The findings are based on a large community cohort of $\mathrm{N}=3097$ adults aged 18 years or older, capturing the views of people across the UK, including key workers and individuals from ethnic minority groups.

- The use of validated measures of mental health allows us to conclude that levels of depression, anxiety and stress significantly exceed previously reported population norms.

- The assessment of demographic and modifiable psychological variables allows us to report on which groups appear to be at greatest risk of increased psychological morbidity, and identifies a role for psychological and public health interventions.

- The cross-sectional design prohibits an analysis of causal relationships and the recruitment of a selfselected community sample has implications for generalisability.

society, our health service and economy. However, the multitude of challenges presented by the pandemic may also pose a significant threat to our psychological health. ${ }^{1}$ Individuals are facing a panoply of stressors including serious illness, bereavement, social distancing and unemployment. The consequences of these stressors for mental health will not be uniform, rather they will be influenced by a range of modifiable and nonmodifiable factors. Identification of the latter will be critical in determining who may be at greatest risk of mental health difficulties and should be the focus of future interventions; while the former can inform approaches to intervention. We report here cross-sectional findings from a community cohort study designed to capture both the mental health sequelae of the COVID-19 pandemic and the modifiable and non-modifiable explanatory factors associated with adverse mental health 
outcomes. Our focus is on the immediate consequences for mental health, as reported during the first 4-6 weeks of social distancing measures being introduced in the UK.

In keeping with its recent emergence, much remains unknown about COVID-19 and its consequences. However, the expectation is that the consequences for both mental and physical health will be profound and far reaching. ${ }^{2}$ With regard to the former, evidence from China attests to this possibility. ${ }^{34}$ as does the experience of previous pandemics. ${ }^{56}$ Indeed, preliminary evidence from the UK suggests that these experiences may be replicated here. ${ }^{7}$ But who might be at greatest risk of mental health difficulties? Individuals at increased risk of the disease and/or adverse outcomes might be expected to experience greater psychological morbidity. For example, the death rate is known to be higher in men and older individuals. ${ }^{8}$ The latter being also more likely to have coexisting conditions and be socially isolated through shielding. The ethnic diversity of countries such as the USA and the UK has also highlighted that individuals from Black, Asian and Minority Ethnic (BAME) backgrounds appear to be affected disproportionately by the disease. ${ }^{10}$ Recent UK data also suggest that key workers, in particular those in social care, are at greater risk of COVID-19-related mortality. ${ }^{8}$

The afore-mentioned factors are, however, largely nonmodifiable, and thus are valuable in understanding who may be at greatest risk of mental health difficulties and in need of intervention. Do modifiable risk factors exist which could be targets for intervention? Stress and coping theory ${ }^{11}$ attests that emotional responses to challenging situations vary according to both our appraisal of stressors and the availability of psychological and social resources. Cognitions are central to the former and evidence from previous pandemics and the COVID-19 pandemic suggest that perceptions of the risk of contracting the disease and increased worry about risks to health are positively associated with adverse mental health outcomes. ${ }^{12-14}$ In terms of resources, social support and its corollary loneliness are among the best established determinants of our emotional responses to stressors. Successive systematic reviews demonstrate poorer mental health outcomes and increased morbidity and mortality in individuals who perceive themselves to be more lonely and lacking in support. ${ }^{15} 16$ Positive mood, now no longer viewed as just the opposite of negative mood, may also confer direct effects on well-being as well as protective effects in challenging situations. ${ }^{11}{ }^{17-19}$ In terms of mental health, evidence suggests that the existence of positive mood reduces the risk of mood disorders by $28 \%$ and anxiety disorders by $53 \%$, and also influences recovery from some mental health conditions. ${ }^{20} 21$

Taken together there is an urgent need to report evidence on the prevalence of mental health problems during the COVID-19 pandemic, to understand who may be at greatest risk, and to explore the psychological and social resources that may mitigate this risk. To that end, we report cross-sectional findings from a community cohort established in April 2020 to prospectively examine the mental health consequences of the pandemic. We focus here on findings from the first survey conducted between 3 April 2020 and 30 April 2020, which coincided with the first 4-6 weeks of social distancing measures being introduced in the UK.

\section{METHODS}

\section{Recruitment and eligibility}

The study was launched on 3 April 2020 with participants recruited in the community through a social and mainstream media campaign involving, but not limited to, Facebook and Twitter. In addition, HRA regulatory approval enabled us to approach National Health Service (NHS) organisations and request they advertise the research through their routine communications. Recruitment continued until 30 April 2020. All media directed potential participants to the study website (www.covidstressstudy.co.uk) through which they accessed the information sheet, consent form and online survey.

Eligibility criteria specified that participants should be: aged 18 or over; able to give informed consent; able to read English; residing in the UK at the time of completing the survey and able to provide a sample of hair at least 1 $\mathrm{cm}$ long. The latter was collected for the determination of the stress biomarker cortisol, which will be the subject of future manuscripts.

\section{Patient and public involvement (PPI)}

We convened a virtual PPI Group to support this research the aims of which were to advise on the development of the survey, the participant information sheet and optimising recruitment and retention. Individuals participated via Microsoft (MS) Teams in one-to-one or group discussions. These discussions informed the length and structure of the survey, language of the information sheet and strategies for recruiting via media and social media. The views of this group were instrumental in achieving our large sample size. This group also advised on providing regular feedback to participants on study findings through the study website and between each wave of data collection.

\section{Sample size}

We did not place an upper limit on participant numbers to enable us to obtain precise estimates of population values and associations, and to be able to examine these in subgroups. As a minimum, we estimated that 252 participants would be required to detect an $\mathrm{R}^{2}$ value of 0.1 , with $90 \%$ power and a $5 \%$ significance level based on inclusion of 20 explanatory variables in a multiple linear regression model.

\section{Procedures}

Consenting participants completed an online survey implemented through Jisc Online Survey (https://www. onlinesurveys.ac.uk/). In the first wave of data collection 
reported here, the survey included validated measures capturing the mental health outcomes: anxiety $(\alpha=0.88)$, depression $(\alpha=0.92)$ and stress $(\alpha=0.76){ }^{22-25}$ Depression was measured using the 9-item Patient Health Questionnaire (PHQ-9) where participants were asked how often, over the past 2 weeks, they were bothered by each problem and selected their answers from a 4-point scale ranging from 'not at all' (0) to 'nearly every day' (3). PHQ-9 scores range from 0 to 27 with higher scores indicating worse levels of depression severity. Anxiety was measured using the 7-item Generalized Anxiety Disorder Scale (GAD-7) where participants were asked how often, during the last 2 weeks, they have been bothered by each problem and selected their responses from a 4-point list: 'not at all' to 'nearly every day' (ie, from 0 to 3). GAD-7 scores range from 0 to 21 with higher scores indicating worse anxiety levels. Stress was measured using the 4-item Perceived Stress Scale (PSS-4) where participants were asked to rate how often they have experienced stress over the last 2 weeks on a 5-point scale ranging from 'Never' (0) to 'Very often' (4). Total scores of PSS-4 range from 0 to 16 with higher scores indicating higher levels of stress.

We also measured modifiable and non-modifiable variables, we hypothesised, would be related to these mental health outcomes due to being (1) associated with an increased risk of contracting COVID-19 and/or adverse disease outcomes or (2) known to be directly associated with adverse mental health outcomes. These were: age, gender, ethnicity, key worker status, living alone, positive mood, worry about contracting COVID-19 and perceived loneliness and risk of COVID-19 (see online supplemental appendix 1). Positive mood was measured using six items from the Scale of Positive and Negative Experience. ${ }^{25}$ Total scores of positive mood range from 6 to 30 with higher scores indicating greater positive mood. COVID-19 risk status, perceived risk of contracting COVID-19, COVID-19 worry, perceived loneliness and living alone were all measured using single items that are described in online supplemental appendix 1 .

\section{Statistical analysis}

We first summarised the outcome variables (depression, anxiety and stress scores) and participant characteristics with appropriate summary statistics and examined histograms and scatterplots. Comparisons with prepandemic normative values were made using independent samples t-tests. Examination of histograms indicated both depression and anxiety scores deviated from a normal distribution; however, transformations or non-parametric tests were not suitable for these comparisons as only summary statistics not individual level data were available for normative data. While t-tests are robust to deviations from normality especially when sample sizes are large,${ }^{26}$ results of these specific tests should be interpreted with appropriate caution. To explore the associations between the outcome variables and non-modifiable and modifiable explanatory factors, we first conducted univariable linear regression analyses (see online supplemental appendix
2). Multivariable linear regression analyses were then used to explore the independent relationships of nonmodifiable factors (age, gender, ethnicity, key worker status, living alone and being in a recognised COVID-19 risk group) on outcome variables. Then, in subsequent models, modifiable explanatory factors (perceived loneliness, perceived risk of COVID-19, positive mood, worry about contracting COVID-19) were added to examine the additional and independent contribution of these factors to explaining variation in the outcome variables. The variable assessing COVID-19 worry was treated as a categorical variable in all models, with 'occasional worry' treated as the reference value as this was the most common response. Assumptions of linear regression (normality and homoscedasticity of residuals, linearity with continuous variables) and presence of outliers were assessed graphically. Multicollinearity was checked for all models using variance inflation factors and found to have acceptable levels. Square root transformations were used for depression and anxiety scores to satisfy assumptions. Robustness of the models was examined by removing data points with large residuals $(<-3$ or $>3)$ and comparing results to the original models. In the vast majority of models, this had no substantive effect on interpretation. Thus, these results are only mentioned where interpretation may be affected. Additionally, as perceived risk of getting COVID-19 was not assessed in those who thought they had had it $(n=519)$ these participants are not represented in final multivariable models. As a sensitivity analysis, models were additionally respecified excluding this explanatory variable (see online supplemental appendix 3).

For depression and anxiety, we also carried out additional analyses dichotomising according to established cut-offs (scores of 10 or greater indicating moderate or severe levels). ${ }^{22}{ }^{23}$ We used multiple logistic regression to estimate ORs with $95 \%$ CIs for their associations with non-modifiable and modifiable variables.

Statistical analyses were performed using STATA (V.16).

\section{Role of sponsor}

The study sponsor did not play a role in the study design, collection; analysis, and interpretation of data; in the writing of the report; or in the decision to submit the paper for publication.

\section{RESULTS}

\section{Cohort characteristics}

The final number of participants recruited was $n=3102$. Of these, five were ineligible due to being less than 18 years old. Thus, yielding $n=3097$ eligible participants. The largest proportion of visitors to the website came direct to the URL $(62 \% / \mathrm{n}=15$ 218), followed by $25 \%$ $(\mathrm{n}=6068)$ via Facebook (the remainder through other websites). The vast majority of respondents accessed the website via a mobile phone $(70 \% / \mathrm{n}=17045)$. The survey was completed in full by $100 \%$ of those who started it, 
consequently there were no missing data, with the exception of age, for which two participants entered nonnumeric values.

Table 1 summarises the main characteristics of the participants, alongside comparative data on UK population values where available. This shows that women were proportionally over-represented and participants older than 75 years, and from Northern Ireland, were underrepresented in the current cohort. Otherwise the sample was reasonably representative of the wider UK population. The cohort had a mean age of 44 years $(\mathrm{SD}=15)$; and $10 \%$ $(\mathrm{n}=296)$ from minority ethnic backgrounds. Fifty per cent $(\mathrm{n}=1559)$ described themselves as key workers $(39 \% /$ $\mathrm{n}=1198$ identifying as working in health and social care). Twenty per cent $(n=649)$ identified themselves as having clinical risk factors, which would put them at increased or greatest risk of COVID-19.

\section{Mental health status}

Table 2 summarises findings in relation to levels of stress, anxiety and depression in the cohort. The mean values for all measures indicate levels that are higher in women than men and decrease with age. Overall mean values are significantly higher than previously reported population norms. ${ }^{27-29}$ For both anxiety and depression, the means for the cohort were higher for both genders compared with their respective population norms, and also for all age ranges between 25 and 64 years. In contrast, both men and women aged over 65 years had anxiety and depression scores consistent with previous population norms. The data suggested no significant differences in stress scores by gender, despite the combined mean score exceeding the population norm. Means scores for depression, anxiety and stress weighted to reflect the most recent UK age and gender distributions (Office for National Statistics, midyear estimates 2019) are presented in online supplemental appendix 4 and show similarly elevated levels in both men and women compared with prepandemic population norms.

Table 3 shows the categorisation of participants in line with established cut-offs for anxiety and depression. This shows $64 \%$ of participants reported symptoms of depression and 57\% reported symptoms of anxiety. When considering the thresholds at which someone would qualify for high intensity psychological support (score of 10 or greater) in the NHS, ${ }^{26}$ we observe that $31.6 \%$ reported moderate to severe depression and $26 \%$ moderate to severe anxiety.

\section{Individuals at greatest risk of mental health problems:} associations with age, gender, ethnicity, living alone and key worker status

When non-modifiable explanatory variables were included in a multivariable model (table 4), we observed that for depression (square-root transformed scores), being younger ( $\mathrm{B}=-0.30,95 \% \mathrm{CI}:-0.33$ to 0.27 per decade), female ( $\mathrm{B}=0.36,95 \%$ CI: 0.25 to 0.47$)$, living alone $(\mathrm{B}=0.34,95 \%$ CI: 0.25 to 0.47$)$ and being in a recognised
Table 1 Participant demographics $(n=3097)$ and UK population values

\begin{tabular}{|c|c|c|}
\hline & \multirow{2}{*}{$\begin{array}{l}\text { Participants } \\
\text { n (\%) }\end{array}$} & UK population \\
\hline & & n (\%) \\
\hline \multicolumn{3}{|l|}{ Gender* } \\
\hline Male & $476(15.4 \%)$ & 32978229 (49.4\%) \\
\hline Female & $2618(84.5 \%)$ & $33818578(50.6 \%)$ \\
\hline Prefer not to say & $3(0.1 \%)$ & NR \\
\hline Age groups (years)* & & 52673433 \\
\hline $18-24$ & $364(11.8 \%)$ & 5647655 (10.7\%) \\
\hline $25-34$ & $528(17.1 \%)$ & $9011381(17.1 \%)$ \\
\hline $35-44$ & $637(20.6 \%)$ & 8415206 (16.0\%) \\
\hline $45-54$ & $690(22.3 \%)$ & $9063137(17.2 \%)$ \\
\hline $55-64$ & $570(18.4 \%)$ & $8161093(15.4 \%)$ \\
\hline $65-74$ & $257(8.3 \%)$ & $6687066(12.7 \%)$ \\
\hline$\geq 75$ & $49(1.6 \%)$ & 5687895 (10.8\%) \\
\hline \multicolumn{3}{|l|}{ Ethnicity† } \\
\hline $\begin{array}{l}\text { White-British, Irish and } \\
\text { other }\end{array}$ & 2796 (90.3\%) & 48209395 (86.0\%) \\
\hline $\begin{array}{l}\text { Asian/Asian British-- } \\
\text { Indian, Pakistani, } \\
\text { Bangladeshi and other }\end{array}$ & $119(3.8 \%)$ & $3820390(6.8 \%)$ \\
\hline $\begin{array}{l}\text { Black/Black British- } \\
\text { Caribbean, African and } \\
\text { other }\end{array}$ & $42(1.4 \%)$ & $1864890(3.3 \%)$ \\
\hline Chinese/Chinese British & $28(0.9 \%)$ & $393141(0.7 \%)$ \\
\hline $\begin{array}{l}\text { Mixed race-White and } \\
\text { Black/Black British }\end{array}$ & $19(0.6 \%)$ & $934416(1.7 \%)$ \\
\hline $\begin{array}{l}\text { Middle Eastern/Middle } \\
\text { Eastern British-Arab, } \\
\text { Turkish and other }\end{array}$ & $23(0.7 \%)$ & NR \\
\hline Mixed race-other & $40(1.3 \%)$ & $289984(0.5 \%)$ \\
\hline Other ethnic group & $25(0.8 \%)$ & $563696(1.0 \%)$ \\
\hline Prefer not to say & $5(0.2 \%)$ & NR \\
\hline \multicolumn{3}{|l|}{ Relationship status } \\
\hline Single, never married & $574(18.5 \%)$ & NR \\
\hline $\begin{array}{l}\text { Single, divorced or } \\
\text { widowed }\end{array}$ & $263(8.5 \%)$ & NR \\
\hline $\begin{array}{l}\text { In a relationship/married } \\
\text { but living apart }\end{array}$ & $254(8.2 \%)$ & NR \\
\hline $\begin{array}{l}\text { In a relationship/married } \\
\text { and cohabiting }\end{array}$ & $1981(64.0 \%)$ & NR \\
\hline Prefer not to say & $25(0.8 \%)$ & NR \\
\hline \multicolumn{3}{|c|}{ Education (highest level of attainment) } \\
\hline No qualifications & $33(1.1 \%)$ & NR \\
\hline $\begin{array}{l}\text { Completed GSCE/CSE/ } \\
\text { O-levels or equivalent }\end{array}$ & $252(8.1 \%)$ & NR \\
\hline $\begin{array}{l}\text { Completed post-16 } \\
\text { vocational course }\end{array}$ & $101(3.3 \%)$ & NR \\
\hline $\begin{array}{l}\text { A-levels or equivalent (at } \\
\text { school until aged 18) }\end{array}$ & $403(13.0 \%)$ & NR \\
\hline $\begin{array}{l}\text { Undergraduate degree or } \\
\text { professional qualification }\end{array}$ & $1306(42.2 \%)$ & NR \\
\hline Postgraduate degree & $976(31.5 \%)$ & NR \\
\hline
\end{tabular}




\section{Table 1 Continued}

\begin{tabular}{|c|c|c|}
\hline & \multirow{2}{*}{$\begin{array}{l}\text { Participants } \\
\text { n (\%) }\end{array}$} & \multirow{2}{*}{$\begin{array}{l}\text { UK population } \\
\text { n (\%) }\end{array}$} \\
\hline & & \\
\hline Prefer not to say & $26(0.8 \%)$ & NR \\
\hline \multicolumn{3}{|l|}{ Place of residence* } \\
\hline South West England & $241(7.8 \%)$ & 5624696 (8.4\%) \\
\hline East Midlands & $762(24.6 \%)$ & $4835928(7.2 \%)$ \\
\hline Yorkshire and Humber & $293(9.5 \%)$ & 5502967 (8.2\%) \\
\hline North East & $147(4.8 \%)$ & 2669941 (4.0\%) \\
\hline East of England & $153(4.9 \%)$ & 6236072 (9.3\%) \\
\hline North West & $357(11.5 \%)$ & 7341196 (11.0\%) \\
\hline South East England & $415(13.4 \%)$ & 9180135 (13.7\%) \\
\hline Greater London & $329(10.6 \%)$ & 8961989 (13.4\%) \\
\hline West Midlands & $165(5.3 \%)$ & 5934037 (8.9\%) \\
\hline Northern Ireland & $8(0.3 \%)$ & 1893667 (2.8\%) \\
\hline Wales & $73(2.4 \%)$ & 3152879 (4.7\%) \\
\hline Scotland & $154(5.0 \%)$ & $5463300(8.2 \%)$ \\
\hline
\end{tabular}

\section{Key worker status}

\begin{tabular}{lcc}
$\begin{array}{l}\text { Health, social care or } \\
\text { relevant related support } \\
\text { worker }\end{array}$ & NR \\
$\begin{array}{l}\text { Teacher or childcare } \\
\text { worker still travelling in } \\
\text { to work }\end{array}$ & $70(2.3 \%)$ & NR \\
$\begin{array}{l}\text { Transport worker still } \\
\text { travelling in to work }\end{array}$ & $1(0.03 \%)$ & NR \\
$\begin{array}{l}\text { Food chain worker (eg, } \\
\text { production, sale and } \\
\text { delivery) }\end{array}$ & $33(1.1 \%)$ & NR \\
\hline
\end{tabular}

\begin{tabular}{|c|c|c|}
\hline $\begin{array}{l}\text { Key public services } \\
\text { worker (eg, justice staff, } \\
\text { religious staff, public } \\
\text { service journalist or } \\
\text { mortuary worker) }\end{array}$ & $22(0.7 \%)$ & NR \\
\hline $\begin{array}{l}\text { Local or national } \\
\text { government worker } \\
\text { delivering essential } \\
\text { public services }\end{array}$ & 41 (1.3\%) & NR \\
\hline $\begin{array}{l}\text { Utility worker (eg, energy, } \\
\text { sewerage and postal } \\
\text { service) }\end{array}$ & $5(0.2 \%)$ & NR \\
\hline $\begin{array}{l}\text { Public safety or national } \\
\text { security worker }\end{array}$ & $11(0.4 \%)$ & NR \\
\hline $\begin{array}{l}\text { Worker involved in } \\
\text { medicines or protective } \\
\text { equipment production or } \\
\text { distribution }\end{array}$ & $10(0.3 \%)$ & NR \\
\hline $\begin{array}{l}\text { Other key worker role not } \\
\text { listed }\end{array}$ & 168 (5.4\%) & NR \\
\hline
\end{tabular}

\begin{tabular}{|c|c|c|}
\hline Not a key worker & $1538(49.7 \%)$ & NR \\
\hline \multicolumn{3}{|c|}{ Living alone (or with others) } \\
\hline Living alone & $406(13.1 \%)$ & NR \\
\hline Living with others & 2691 (86.9\%) & NR \\
\hline COVID-19 risk group & & \\
\hline
\end{tabular}

Continued
Table 1 Continued

\begin{tabular}{|c|c|c|}
\hline & Participants & UK population \\
\hline & n (\%) & n (\%) \\
\hline $\begin{array}{l}\text { Most at risk (eg, suffering } \\
\text { from advanced cancer, } \\
\text { severe asthma/COPD) }\end{array}$ & $121(3.9 \%)$ & NR \\
\hline $\begin{array}{l}\text { At increased risk (eg, } \\
\text { being pregnant, aged } \\
\text { over } 70 \text { ) }\end{array}$ & $528(17.1 \%)$ & NR \\
\hline Not at-risk & 2448 (79.0\%) & NR \\
\hline
\end{tabular}

*UK population estimates from Office for National Statistics, midyear estimates 2019.

†UK population estimates from 2011 census data.

NR, not reported or not available.

risk group for COVID-19 ('most at risk' group: $\mathrm{B}=0.56$, 95\% CI: 0.35 to 0.77 ; 'increased risk' group: $\mathrm{B}=0.27,95 \%$ CI: 0.16 to 0.38 ) were all independently significantly associated with greater levels of depression. This model accounted for $14 \%$ of the variance in depression scores. These results were replicated when considering depression as a binary outcome (ie, cases requiring high intensity intervention vs not) with those in recognised risk groups for COVID-19 being more likely to have a depression score above 10 with $98 \%$ increased odds in the 'most at risk' group and 63\% increased odds in those in the 'increased risk' group compared with those in neither risk group. In addition, women had a $50 \%$ increased odds of having depression scores above 10 and living alone was associated with a $53 \%$ increase.

For anxiety (square-root transformed scores) being younger ( $\mathrm{B}=-0.26,95 \% \mathrm{CI}$ : -0.29 to 0.23 per decade), female ( $\mathrm{B}=0.43,95 \%$ CI: 0.32 to 0.55$)$, being a key worker $(\mathrm{B}=0.09,95 \%$ CI: 0.01 to 0.18$)$ and being in a recognised COVID-19 risk group ('most at risk' group: $\mathrm{B}=0.42,95 \%$ CI: 0.20 to 0.63 ; 'increased risk' group: $\mathrm{B}=0.21,95 \% \mathrm{CI}$ : 0.10 to 0.33 ) were independently significantly associated with greater levels of anxiety (table 5). This model accounted for $11 \%$ of the variance in anxiety scores and these results were replicated when considering anxiety as a binary outcome (ie, cases requiring high intensity intervention vs not), with the exception that being a key worker was no longer a statistically significant independent predictor.

For stress scores, being younger $(\mathrm{B}=-0.56,95 \%$ CI: -0.64 to 0.49 per decade), female ( $\mathrm{B}=0.78,95 \%$ CI: 0.46 to 1.09$)$, living alone $(\mathrm{B}=0.46,95 \%$ CI: 0.12 to 0.79$)$, being from a BAME background $(\mathrm{B}=0.44,95 \%$ CI: 0.05 to 0.82 ) and being from an identified COVID-19 risk group ('most at risk' group: $\mathrm{B}=1.10,95 \%$ CI: 0.51 to 1.68 ; 'increased risk' group: $\mathrm{B}=0.40,95 \% \mathrm{CI}: 0.09$ to 0.71 ) were all independently significantly associated with greater stress scores. In robustness analyses, when removing large standardised residuals $(<-3$ or $>3)$ being a key worker was also a statistically significant independent predictor $(\mathrm{B}=-0.22,95 \%$ CI: -0.45 to 0.002$)$ such that being a key worker was associated with lower stress scores). Together 


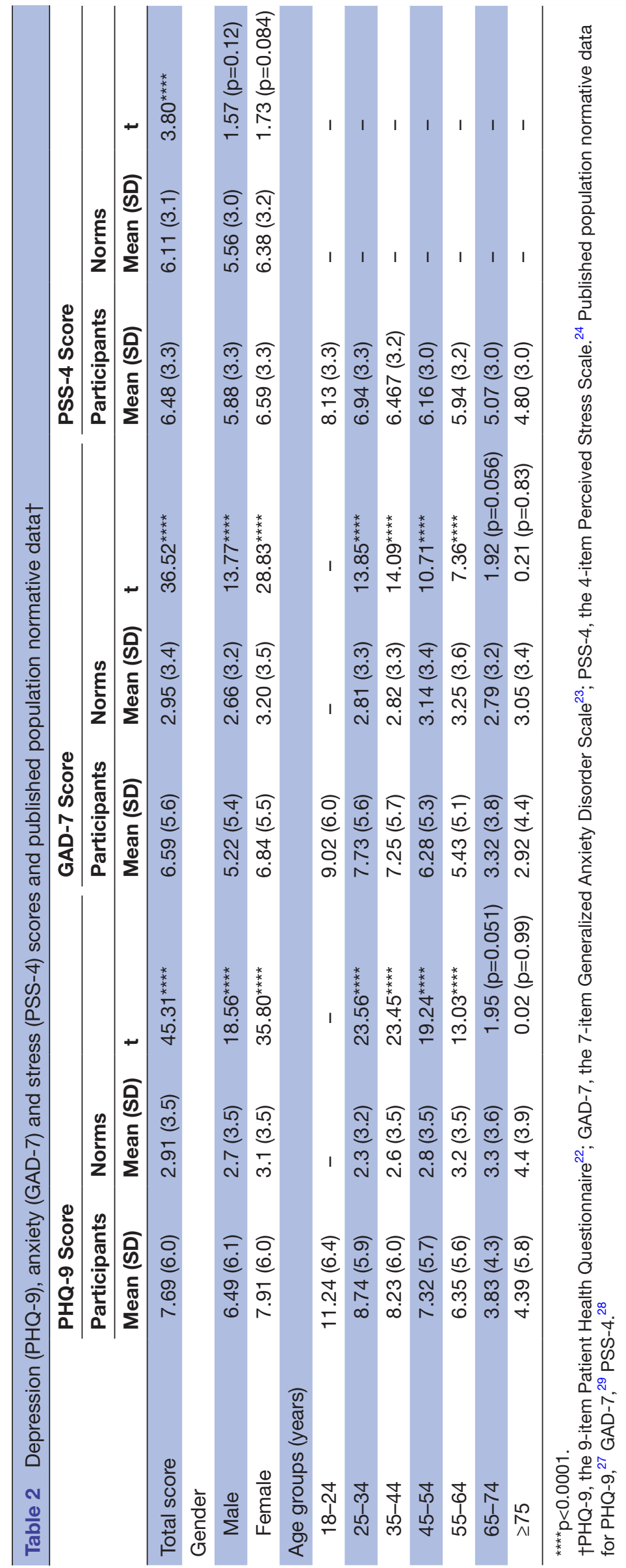


Table 3 Prevalence of depressive and anxiety cases ${ }^{\star}$

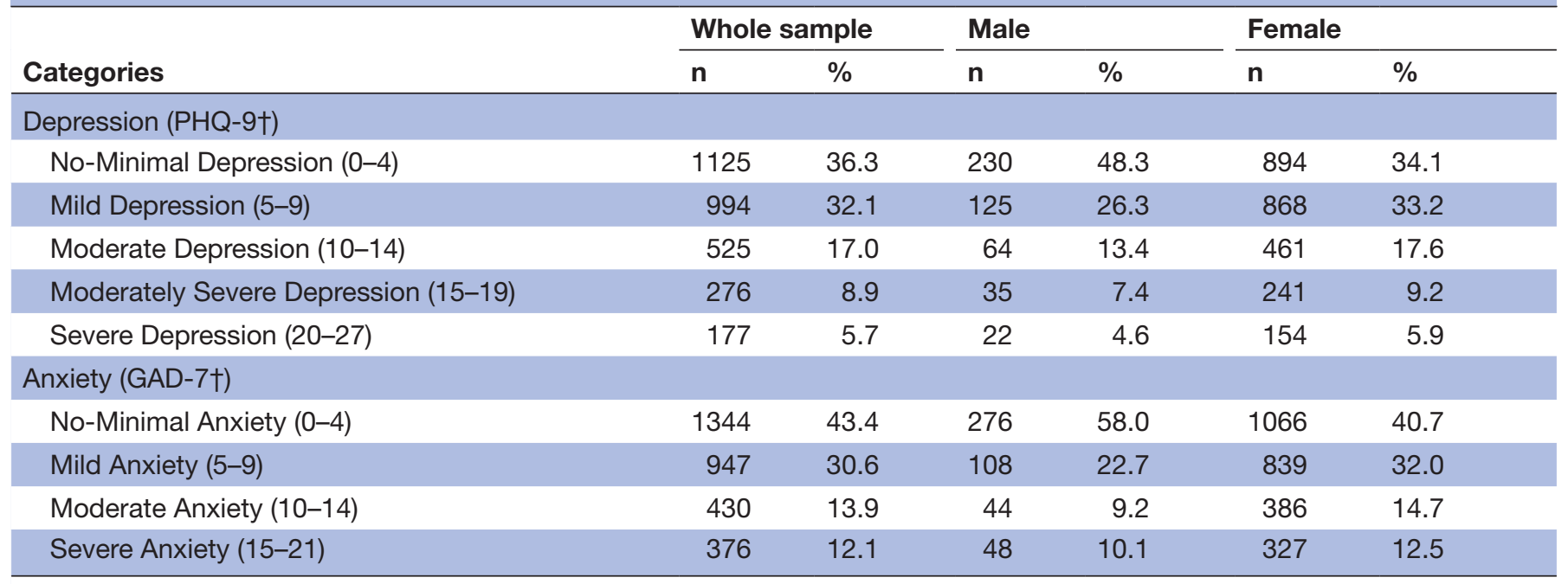

${ }^{*}$ Cut-offs for categories in line with published guidelines for PHQ- $9{ }^{23}$ and GAD-7. ${ }^{25}$

†PHQ-9, the 9-item Patient Health Questionnaire ${ }^{19}$; GAD-7, the 7-item Generalized Anxiety Disorder Scale. ${ }^{20}$

the model accounted for $7 \%$ of the variance in stress scores (table 6).

\section{Individuals at greatest risk of mental health problems: associations with perceived risk of COVID-19, perceived Ioneliness, COVID-19 worry and positive mood}

Table 7 shows scores for modifiable explanatory variables (perceived risk, perceived loneliness, COVID-19 worry and positive mood) across the whole sample, as well as by gender and age-groups.

When modifiable explanatory variables were added into the multivariable model for depression: this revealed that greater perceived loneliness $(\mathrm{B}=0.10,95 \%$ CI: 0.09 to 0.12$)$, lower positive $\operatorname{mood}(\mathrm{B}=-0.12,95 \% \mathrm{CI}:-0.12$ to 0.11 ) and greater than occasional worry about getting COVID-19 (much of time: $\mathrm{B}=0.26,95 \%$ CI: 0.16 to 0.36 ; most of time: $\mathrm{B}=0.30,95 \%$ CI: 0.12 to 0.48 ) were all independently and significantly associated with greater levels of depression, in addition to age, gender and being in a recognised COVID-19 risk group. The model accounted for $57 \%$ of the variance in depression scores. These results were largely replicated when considering depression as a binary outcome although gender and being in the 'most at risk' group were no longer statistically significant (table 8).

For anxiety, the model revealed that greater perceived loneliness $(\mathrm{B}=0.06,95 \% \mathrm{CI}: 0.04$ to 0.07$)$, lower positive $\operatorname{mood}(\mathrm{B}=-0.12,95 \% \mathrm{CI}:-0.13$ to 0.11$)$ and greater perceived risk of COVID-19 ( $\mathrm{B}=0.04,95 \%$ CI: 0.02 to $0.05)$ were all independently and significantly associated with greater anxiety, in addition to the non-modifiable factors of being younger, female and living alone. Further, those participants who experienced greater than occasional worry about getting COVID-19 were significantly more likely to have higher levels of anxiety (much of time: $\mathrm{B}=0.57,95 \%$ CI: 0.47 to 0.68 ; most of time: $\mathrm{B}=0.87$ to $95 \%$ CI: 0.68 to 1.06 ); with those who did not worry at all about getting COVID-19 being likely to have lower anxiety ( $\mathrm{B}=-0.18$ to $95 \%$ CI: -0.28 to 0.09 ). The model accounted for $54 \%$ of the variance in anxiety scores. These results were largely replicated when considering anxiety as a binary outcome, although gender and not worrying at all about getting COVID-19 were no longer statistically significant (table 9).

The multivariable model for stress scores showed that greater perceived loneliness $(\mathrm{B}=0.19,95 \%$ CI: 0.15 to 0.23 ), lower positive mood ( $\mathrm{B}=-0.38$ to $95 \%$ CI: -0.40 to 0.36 ), greater than occasional worry about getting COVID-19 (much of time: $\mathrm{B}=0.37,95 \%$ CI: 0.10 to 0.63 ; most of time: $\mathrm{B}=1.02,95 \% \mathrm{CI}: 0.54$ to 1.50$)$ and greater perceived risk of getting COVID-19 (B=0.06, 95\% CI:0.02 to 0.11 ) were all independently and significantly associated with greater stress, in addition to being younger, female, living alone and not being a key worker. In robustness analyses, when removing large standardised residuals $(<-3$ or $>3)$ having a BAME background was also a statistically significant independent predictor $(\mathrm{B}=0.29$, 95\% CI: 0.00 to 0.58 ). This model accounted for $57 \%$ of the variance in stress scores (table 10).

\section{DISCUSSION}

We report findings from the first wave of data collection from a community cohort study established in the UK to prospectively examine the mental health consequences of the COVID-19 pandemic. Our results pertain to the experiences of people within the first 4-6 weeks of social distancing measures being introduced, and focus on self-reported depression, anxiety and stress scores. The findings indicated that mean levels of depression, anxiety and stress significantly exceeded previously published population norms. ${ }^{27-29}$ Models examining the relationship between these mental health outcomes 
Table 4 Regression models showing associations between non-modifiable explanatory variables and depression scores

Regression

coefficient

(B) $\quad 95 \% \mathrm{Cl}$ lower $\quad 95 \% \mathrm{Cl}$ upper $\quad$ B $\quad$ P value

\begin{tabular}{|c|c|c|c|c|c|}
\hline \multicolumn{6}{|l|}{ PHQ-9 total score $\dagger$} \\
\hline Age (per decade) & -0.30 & -0.33 & -0.27 & -0.36 & $<0.0001^{\star \star \star *}$ \\
\hline Female & 0.36 & 0.25 & 0.47 & 0.11 & $<0.0001^{\star \star \star \star}$ \\
\hline Live alone & 0.33 & 0.21 & 0.45 & 0.09 & $<0.0001^{\star * \star *}$ \\
\hline BAME background & 0.03 & -0.11 & 0.17 & 0.01 & 0.70 \\
\hline Key worker & 0.08 & -0.00 & 0.16 & 0.03 & 0.07 \\
\hline \multicolumn{6}{|l|}{ Risk groupł } \\
\hline Most at risk & 0.56 & 0.35 & 0.77 & 0.09 & $<0.0001^{\star \star \star *}$ \\
\hline Increased risk & 0.27 & 0.16 & 0.38 & 0.08 & $<0.0001^{\star * \star *}$ \\
\hline
\end{tabular}

Adjusted $R^{2}=0.14, \mathrm{n}=3090$

\begin{tabular}{|c|c|c|c|c|c|}
\hline & OR & $95 \% \mathrm{Cl}$ lower & $95 \% \mathrm{Cl}$ upper & $\beta$ & $P$ value \\
\hline \multicolumn{6}{|l|}{ PHQ-9 ‘cases'§ } \\
\hline Age (per decade) & 0.65 & 0.61 & 0.69 & -1.38 & $<0.0001^{\star \star \star *}$ \\
\hline Live alone & 1.53 & 1.21 & 1.93 & 0.31 & $<0.001^{\star \star *}$ \\
\hline BAME background & 1.14 & 0.88 & 1.48 & 0.08 & 0.31 \\
\hline \multicolumn{6}{|l|}{ Risk groupł } \\
\hline Most at risk & 1.98 & 1.33 & 2.94 & 0.28 & $<0.001^{\star \star *}$ \\
\hline $\begin{array}{l}\text { Increased risk } \\
\text { Pseudo } R^{2}=0.07, n=3090\end{array}$ & 1.63 & 1.31 & 2.02 & 0.39 & $<0.0001^{\star \star \star *}$ \\
\hline
\end{tabular}

${ }^{* * \star *} \mathrm{p}<0.001,{ }^{* * * *} \mathrm{p}<0.0001$.

†A square-root transformation was applied to the dependent variable.

$\ddagger$ Comparison reference group 'I am in neither risk category'.

$\S A$ 'case' is defined as a PHQ-9 Score greater than or equal to 10, at which level someone would qualify for high intensity psychological support in the National Health Service.

BAME, Black, Asian and Minority Ethnic; PHQ-9, 9-item Patient Health Questionnaire.

and non-modifiable explanatory factors accounted for only a modest proportion of the variance $(7 \%-14 \%)$. Increased depression was associated with being younger, female, living alone and being in a recognised COVID-19 risk group; increased anxiety was associated with being younger, female and being in a recognised risk group; and increased stress was associated with being younger, female, living alone, being from a BAME background and a recognised risk group. In contrast, when we added the hypothesised modifiable variables into our multivariable models we observed that the final models accounted for a much larger proportion of the variance $(54 \%-57 \%)$ with significant independent effects emerging for lower positive mood and greater perceived loneliness and worry about getting COVID-19 associated with higher scores for all three outcomes, as well as greater perceived risk of COVID-19 emerging as significant for anxiety and stress.

These findings highlight a number of issues worthy of discussion. First, we acknowledge several limitations. These include the cross-sectional design that impedes an analysis of cause and effect. Thus, while we report on several significant associations it remains the case that we cannot be certain whether the relationships are causal, or simply due to the presence of other unmeasured characteristics; or indeed be certain of the direction of these relationships (ie, reverse causality). For example, it is possible that lower positive mood leads to greater depression and that greater depression leads to lower positive mood.

A further limitation concerns the absence of information on pre-existing mental health conditions. This could have influenced the severity and prevalence of psychological morbidity reported in this study. ${ }^{1}$ Furthermore, the self-selected community cohort design could have introduced sampling biases limiting the generalisability of our findings. For example, the spread of participants across the UK was limited and individuals with an interest in and experience of mental health difficulties may have been over-represented. Furthermore, typical of previous online surveys concerned with mental health, women were overrepresented in our sample. ${ }^{30}$ Thus, while our comparisons with UK census and Office of National Statistics data (see 
Table 5 Regression models showing associations between non-modifiable explanatory variables and anxiety scores

\begin{tabular}{|c|c|c|c|c|c|}
\hline & B & $95 \% \mathrm{CI}$ lower & 95\% Cl upper & $\boldsymbol{\beta}$ & $P$ value \\
\hline \multicolumn{6}{|l|}{ GAD-7 total score $\dagger$} \\
\hline Age (per decade) & -0.26 & -0.29 & -0.23 & -0.31 & $<0.0001^{\star \star \star \star}$ \\
\hline Live alone & -0.04 & -0.16 & 0.08 & -0.01 & 0.51 \\
\hline BAME background & 0.02 & -0.12 & 0.16 & 0.00 & 0.81 \\
\hline Most at risk & 0.42 & 0.20 & 0.63 & 0.07 & $<0.001^{\star \star \star}$ \\
\hline Increased risk & 0.21 & 0.10 & 0.33 & 0.07 & $<0.001^{\star \star *}$ \\
\hline \multicolumn{6}{|l|}{ Adjusted $R^{2}=0.11, n=3090$} \\
\hline & OR & $95 \% \mathrm{Cl}$ lower & 95\% Cl upper & $\beta$ & $P$ value \\
\hline Live alone & 1.00 & 0.77 & 1.30 & 0.00 & 0.98 \\
\hline BAME background & 1.15 & 0.88 & 1.50 & 0.09 & 0.32 \\
\hline Key worker & 1.14 & 0.97 & 1.35 & 0.15 & 0.12 \\
\hline \multicolumn{6}{|l|}{ Risk group $\ddagger$} \\
\hline Most at risk & 1.78 & 1.18 & 2.67 & 0.25 & $0.005^{\star *}$ \\
\hline Increased risk & 1.30 & 1.03 & 1.64 & 0.22 & $0.03^{*}$ \\
\hline Pseudo $R^{2}=0.05, n=3090$ & & & & & \\
\hline
\end{tabular}

${ }^{*} p<0.05,{ }^{* *} p<0.01,{ }^{* \star *} p<0.001,{ }^{* * * *} p<0.0001$.

†A square-root transformation was applied to the dependent variable.

‡Comparison reference group 'I am in neither risk category'.

$\S A$ 'case' is defined as a GAD-7 Score greater than or equal to 10, at which level someone would qualify for high intensity psychological support in the National Health Service.

BAME, Black, Asian and Minority Ethnic; GAD-7, 7-item Generalized Anxiety Disorder Scale.

table 1) indicated that across many parameters our cohort were largely representative of the UK population; and our supplementary analysis (online supplemental appendix 4) weighted by the age and gender distribution in the UK in 2019 confirmed the presence of increased stress, anxiety and depression compared with prepandemic norms, we acknowledge that these areas of sampling bias have implications for the generalisability of our findings. We also note that, typical of online surveys, we are unable to determine the extent to which our findings were

Table 6 Regression model showing associations between non-modifiable explanatory variables and stress scores

\begin{tabular}{|c|c|c|c|c|c|}
\hline & B & $95 \% \mathrm{Cl}$ lower & $95 \% \mathrm{Cl}$ upper & $\boldsymbol{\beta}$ & $P$ value \\
\hline \multicolumn{6}{|c|}{ 4-item Perceived Stress Scale total score } \\
\hline Age (per decade) & -0.56 & -0.64 & -0.49 & -0.26 & $<0.0001^{\star \star \star \star}$ \\
\hline Live alone & 0.46 & 0.12 & 0.79 & 0.05 & $0.008^{\star *}$ \\
\hline $\begin{array}{l}\text { Black, Asian and Minority Ethnic } \\
\text { background }\end{array}$ & 0.44 & 0.05 & 0.82 & 0.04 & $0.03^{*}$ \\
\hline \multicolumn{6}{|l|}{ Risk group $†$} \\
\hline Most at risk & 1.10 & 0.51 & 1.68 & 0.06 & $<0.001^{\star \star \star}$ \\
\hline Increased risk & 0.40 & 0.09 & 0.71 & 0.05 & $0.01^{*}$ \\
\hline
\end{tabular}

${ }^{*} p<0.05,{ }^{* *} p<0.01,{ }^{* * *} p<0.001,{ }^{* * * *} p<0.0001$.

†Comparison reference group 'I am in neither risk category'. 


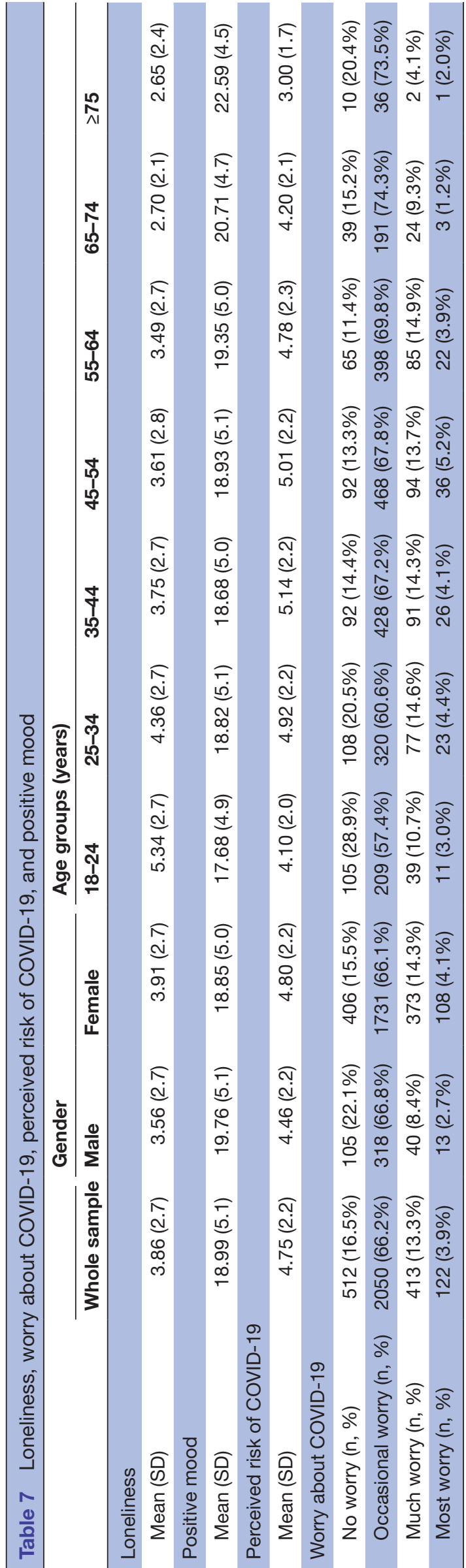

affected by non-response bias. We took a number of steps to minimise this including ensuring brevity of the survey, designing it in conjunction with our virtual PPI Group and conducting supplementary analyses weighted to reflect the most recent UK age and gender distributions. But this remains a potential source of bias in our findings. Finally, we also note that our comparisons with normative data were limited to the most recent data we were able to access. For stress and depression, comparisons were made with data reported in 2013, but for anxiety it was 2008. We acknowledge there may have been population shifts in mental health in the intervening years which may account, in part, for some of the increase in mental health difficulties reported here.

A second observation is that both mean scores and measures of caseness suggest that the COVID-19 pandemic may have contributed to an increased prevalence of mental health difficulties in the UK. This is true for depression, generalised anxiety disorder and stress and is in keeping with observations from other countries. ${ }^{34}$ Indeed, the proportion of participants who would require intensive support for depression and anxiety in the NHS does not compare favourably with recent historical estimates of the prevalence of mental health problems in the UK. For example, the 2014 Office of National Statistics report on adult psychiatric morbidity reported a prevalence of $17 \%$ for six different common mental disorders. ${ }^{31}$ The prevalence of depression alone in the context of this pandemic is almost double this. However, what we cannot determine from this work is whether the apparent increase in psychological morbidity is an expected, but short-term response to the pandemic. Or if this distress is sustained over time and likely to warrant intervention. Longitudinal follow-ups of this and other cohorts will provide valuable data in this regard. Furthermore, as noted above, we also cannot be certain how much of the increase in psychological morbidity is attributable to the pandemic or a more general trend towards increased mental health concerns that has been suggested by some in recent years. ${ }^{32}$

Third, the non-modifiable explanatory variables significantly associated with increased levels for all three of our mental health outcomes were being younger, female and in a recognised COVID-19 risk group. The findings regarding gender and age are of course recognised risk factors for mental health ${ }^{33}$ and are also consistent with unpublished data from another UK community cohort recruited during the COVID-19 pandemic with a similar gender profile to our own, ${ }^{34}$ suggesting that these groups may be the most in need of intervention. They are also, in part, consistent with our hypothesis that the greatest psychological morbidity would be observed in individuals at greatest risk of COVID-19. But they also clearly illustrate that for some (eg, younger participants), the experience of psychological morbidity may be unrelated to their actual risk of COVID-19. These results may reflect the fact that the pandemic has resulted in a panoply of challenges likely to affect mental health that go beyond the disease 
Table 8 Regression models showing associations between modifiable explanatory variables and depression scores

$\begin{array}{lllll}\text { B } & 95 \% \mathrm{Cl} \text { lower } & 95 \% \mathrm{Cl} \text { upper } & \boldsymbol{\beta} & \mathrm{P} \text { value }\end{array}$

\begin{tabular}{|c|c|c|c|c|c|}
\hline \multicolumn{6}{|l|}{ PHQ-9 total score $†$} \\
\hline Age (per decade) & -0.19 & -0.21 & -0.17 & -0.24 & $<0.0001^{\star \star \star \star}$ \\
\hline Female & 0.19 & 0.10 & 0.28 & 0.06 & $<0.0001^{\star \star \star \star}$ \\
\hline Live alone & 0.01 & -0.09 & 0.11 & 0.00 & 0.79 \\
\hline BAME background & -0.02 & -0.14 & 0.09 & -0.01 & 0.67 \\
\hline Key worker & 0.02 & -0.05 & 0.09 & 0.01 & 0.52 \\
\hline \multicolumn{6}{|l|}{ Risk group } \\
\hline Most at risk & 0.26 & 0.09 & 0.43 & 0.04 & $0.002^{\star \star}$ \\
\hline Increased risk & 0.20 & 0.11 & 0.29 & 0.06 & $<0.0001^{* * * *}$ \\
\hline Perceived loneliness (per unit) & 0.10 & 0.09 & 0.12 & 0.22 & $<0.0001^{\star \star \star *}$ \\
\hline Positive mood (per unit) & -0.12 & -0.12 & -0.11 & -0.48 & $<0.0001^{\star \star \star *}$ \\
\hline \multicolumn{6}{|l|}{ COVID-19 worry§ } \\
\hline No worry & 0.00 & -0.09 & 0.09 & 0.00 & 0.97 \\
\hline Much of time & 0.26 & 0.16 & 0.36 & 0.07 & $<0.0001^{\star \star \star \star}$ \\
\hline Most of time & 0.30 & 0.12 & 0.48 & 0.05 & $0.001^{* *}$ \\
\hline Perceived risk of COVID-19 (per unit) & 0.01 & -0.00 & 0.03 & 0.02 & 0.13 \\
\hline \multicolumn{6}{|l|}{ Adjusted $R^{2}=0.57, n=2494$} \\
\hline & OR & 95\% Cl lower & $95 \% \mathrm{Cl}$ upper & $\boldsymbol{\beta}$ & $P$ value \\
\hline \multicolumn{6}{|l|}{ PHQ-9 'cases' } \\
\hline Age (per decade) & 0.66 & 0.61 & 0.72 & -1.38 & $<0.0001^{\star \star \star \star}$ \\
\hline Female & 1.08 & 0.78 & 1.50 & 0.06 & 0.66 \\
\hline Live alone & 0.88 & 0.61 & 1.25 & -0.10 & 0.47 \\
\hline BAME background & 0.96 & 0.65 & 1.40 & -0.03 & 0.82 \\
\hline Key worker & 1.09 & 0.86 & 1.38 & 0.09 & 0.49 \\
\hline \multicolumn{6}{|l|}{ Risk group $\ddagger$} \\
\hline Most at risk & 1.28 & 0.74 & 2.21 & 0.11 & 0.37 \\
\hline Increased risk & 1.61 & 1.19 & 2.19 & 0.40 & $0.002^{\star *}$ \\
\hline Perceived loneliness (per unit) & 1.22 & 1.16 & 1.28 & 1.19 & $<0.0001^{\star \star \star *}$ \\
\hline Positive mood (per unit) & 0.76 & 0.74 & 0.79 & -3.01 & $<0.0001^{\star \star \star \star}$ \\
\hline \multicolumn{6}{|l|}{ COVID-19 worry§ } \\
\hline No worry & 1.02 & 0.73 & 1.44 & 0.02 & 0.90 \\
\hline Much of time & 1.67 & 1.23 & 2.28 & 0.38 & $0.001^{* *}$ \\
\hline Most of time & 2.02 & 1.13 & 3.62 & 0.29 & $0.02^{*}$ \\
\hline $\begin{array}{l}\text { Perceived risk of COVID-19 (per unit) } \\
\text { Pseudo } R^{2}=0.36, n=2494\end{array}$ & 1.04 & 0.98 & 1.10 & 0.18 & 0.20 \\
\hline
\end{tabular}

${ }^{*} \mathrm{p}<0.05,{ }^{* \star} \mathrm{p}<0.01,{ }^{\star \star \star \star} \mathrm{p}<0.0001$

$\dagger$ A square-root transformation was applied to the dependent variable.

‡Comparison reference group 'I am in neither risk category'.

$\S$ Comparison reference group 'I occasionally worry about getting COVID-19'.

IA 'case' is defined as a PHQ-9 Score greater than or equal to 10, at which level someone would qualify for high intensity psychological support in the National Health Service.

BAME, Black, Asian and Minority Ethnic; PHQ-9, 9-item Patient Health Questionnaire.

itself. It could be hypothesised, for example, that some of the more immediate consequences such as unemployment, financial concerns and increased domestic violence would disproportionately affect younger people and women and this may explain our findings.
A fourth, and related issue, is that although being younger, female and in a recognised COVID-19 risk group were consistently associated with poorer mental health, the relationship was modest, accounting for, at best, $14 \%$ of the variance. In contrast, the modifiable 
Table 9 Regression models showing associations between modifiable explanatory variables and anxiety

$\begin{array}{lllll}\text { B } & 95 \% \mathrm{Cl} \text { lower } & 95 \% \mathrm{Cl} \text { upper } & \boldsymbol{\beta} & \text { P value }\end{array}$

\begin{tabular}{|c|c|c|c|c|c|}
\hline \multicolumn{6}{|l|}{ GAD-7 total score $\dagger$} \\
\hline Age (per decade) & -0.16 & -0.18 & -0.14 & -0.20 & $<0.0001^{* \star \star \star}$ \\
\hline Female & 0.25 & 0.16 & 0.34 & 0.07 & $<0.0001^{\star * \star *}$ \\
\hline Live alone & -0.25 & -0.36 & -0.15 & -0.07 & $<0.0001^{* \star \star \star}$ \\
\hline BAME background & -0.08 & -0.19 & 0.04 & -0.02 & 0.19 \\
\hline Key worker & -0.03 & -0.11 & 0.04 & -0.01 & 0.34 \\
\hline \multicolumn{6}{|l|}{ Risk group } \\
\hline Most at risk & 0.02 & -0.15 & 0.19 & 0.00 & 0.83 \\
\hline Increased risk & 0.07 & -0.02 & 0.16 & 0.02 & 0.13 \\
\hline Perceived loneliness (per unit) & 0.06 & 0.04 & 0.07 & 0.12 & $<0.0001^{\star \star \star \star}$ \\
\hline Positive mood (per unit) & -0.12 & -0.13 & -0.11 & -0.48 & $<0.0001^{\star \star \star *}$ \\
\hline \multicolumn{6}{|l|}{ COVID-19 worry§ } \\
\hline No worry & -0.18 & -0.28 & -0.09 & -0.05 & $<0.001^{\star \star \star}$ \\
\hline Much of time & 0.57 & 0.47 & 0.68 & 0.15 & $<0.0001^{\star \star \star \star}$ \\
\hline Most of time & 0.87 & 0.68 & 1.06 & 0.13 & $<0.0001^{\star \star \star *}$ \\
\hline Perceived risk of COVID-19 (per unit) & 0.04 & 0.02 & 0.05 & 0.06 & $<0.0001^{\star \star \star \star}$ \\
\hline \multicolumn{6}{|l|}{ Adjusted $R^{2}=0.54, n=2494$} \\
\hline & OR & $95 \% \mathrm{Cl}$ lower & $95 \% \mathrm{Cl}$ upper & $\beta$ & $P$ value \\
\hline \multicolumn{6}{|l|}{ GAD-7 'cases'ๆ } \\
\hline Age (per decade) & 0.69 & 0.63 & 0.76 & -1.32 & $<0.0001^{\star * \star *}$ \\
\hline Female & 1.17 & 0.82 & 1.67 & 0.13 & 0.38 \\
\hline Live alone & 0.67 & 0.46 & 0.99 & -0.31 & $0.04^{*}$ \\
\hline BAME background & 0.96 & 0.65 & 1.44 & -0.03 & 0.86 \\
\hline Key worker & 0.89 & 0.70 & 1.15 & -0.13 & 0.38 \\
\hline \multicolumn{6}{|l|}{ Risk group $\ddagger$} \\
\hline Most at risk & 0.89 & 0.51 & 1.55 & -0.05 & 0.67 \\
\hline Increased risk & 0.92 & 0.66 & 1.29 & -0.07 & 0.64 \\
\hline Perceived loneliness (per unit) & 1.11 & 1.06 & 1.17 & 0.68 & $<0.0001^{\star \star \star \star}$ \\
\hline Positive mood (per unit) & 0.77 & 0.75 & 0.80 & -3.08 & $<0.0001^{\star \star \star \star}$ \\
\hline \multicolumn{6}{|l|}{ COVID-19 worry§ } \\
\hline No worry & 0.75 & 0.52 & 1.09 & -0.24 & 0.13 \\
\hline Much of time & 3.90 & 2.88 & 5.29 & 1.07 & $<0.0001^{\star * * *}$ \\
\hline Most of time & 11.63 & 5.91 & 22.90 & 1.06 & $<0.0001^{\star \star \star \star}$ \\
\hline Perceived risk of COVID-19 (per unit) & 1.07 & 1.01 & 1.14 & 0.35 & $0.02^{*}$ \\
\hline
\end{tabular}

${ }^{*} \mathrm{p}<0.05,{ }^{* * *} \mathrm{p}<0.001,{ }^{* * * *} \mathrm{p}<0.0001$.

†A square-root transformation was applied to the dependent variable.

$\ddagger$ Comparison reference group 'I am in neither risk category'.

§Comparison reference group 'I occasionally worry about getting COVID-19'.

IA 'case' is defined as a GAD-7 Score greater than or equal to 10, at which level someone would qualify for high intensity psychological support in the National Health Service.

BAME, Black, Asian and Minority Ethnic; GAD-7, 7-item Generalized Anxiety Disorder Scale.

explanatory measures when added to the multivariable models accounted for $54 \%-57 \%$ of the total variance, with greater perceived loneliness, worry about getting COVID-19 and lower positive mood strongly associated with all three outcomes. These findings are encouraging as they suggest that there is considerable potential to develop interventions to mitigate the mental health effects of the pandemic. ${ }^{35}$ But they also signal a role for public health interventions. For example, a robust and effective contact tracing system with regional level data 
Table 10 Regression model showing associations between modifiable explanatory variables and stress scores

\begin{tabular}{|c|c|c|c|c|c|}
\hline & B & $95 \% \mathrm{Cl}$ lower & $95 \%$ Cl upper & $\boldsymbol{\beta}$ & $P$ value \\
\hline \multicolumn{6}{|l|}{ 4-item Perceived Stress Scale total score } \\
\hline Age (per decade) & -0.25 & -0.31 & -0.18 & -0.12 & $<0.0001^{\star \star \star \star}$ \\
\hline Live alone & -0.41 & -0.67 & -0.14 & -0.04 & $0.002^{\star \star}$ \\
\hline Black, Asian and Minority Ethnic background & 0.26 & -0.04 & 0.55 & 0.02 & 0.09 \\
\hline \multicolumn{6}{|l|}{ Risk group $\ddagger$} \\
\hline Most at risk & 0.03 & -0.41 & 0.47 & 0.00 & 0.90 \\
\hline Increased risk & 0.02 & -0.21 & 0.26 & 0.00 & 0.83 \\
\hline Perceived loneliness (per unit) & 0.19 & 0.15 & 0.23 & 0.15 & $<0.0001^{\star \star \star \star}$ \\
\hline Positive mood (per unit) & -0.38 & -0.40 & -0.36 & -0.60 & $<0.0001^{\star \star \star \star}$ \\
\hline \multicolumn{6}{|l|}{ COVID-19 worry $†$} \\
\hline Much of time & 0.37 & 0.10 & 0.63 & 0.04 & $0.007^{\star \star}$ \\
\hline Most of time & 1.02 & 0.54 & 1.50 & 0.06 & $<0.0001^{\star \star \star *}$ \\
\hline Perceived risk of COVID-19 (per unit) & 0.06 & 0.02 & 0.11 & 0.04 & $0.004^{\star \star}$ \\
\hline Adjusted $R^{2}=0.57, n=2494$ & & & & & \\
\hline
\end{tabular}

${ }^{*} \mathrm{p}<0.05,{ }^{* *} \mathrm{p}<0.01,{ }^{* * *} \mathrm{p}<0.001,{ }^{* * * *} \mathrm{p}<0.0001$.

†Comparison reference group 'I occasionally worry about getting COVID-19'.

$\ddagger$ Comparison reference group 'I am in neither risk category'.

could do much to allay people's worries about contracting the infection and also increase social participation which, in turn, would benefit perceived loneliness. Clear and consistent public health messaging regarding the use of face masks to reduce infection risk could be another effective strategy. Viewed this way, these public health interventions could simultaneously reduce the risk of COVID-19 infection as well as help to manage some of the concomitant psychological distress. There is, of course, still likely to be increased demand for mental health services in response to the pandemic. However, our data suggest that public health control measures commonly used in response to epidemics and pandemics may also have a role to play.

A final issue concerns the effects of the pandemic beyond mental health. It is well known that when negative mood states persist over time they result in the dysregulation of physiological systems involved in the regulation of the immune system. ${ }^{36}$ Thus, there exists significant potential for the psychological harm inflicted by the pandemic to translate into physical harm. This could include an increased susceptibility to the virus, worse outcomes if infected, or indeed poorer responses to vaccinations in the future ${ }^{36}$ Studies providing longitudinal data on the prevalence of psychological morbidity and appropriate biomarkers (eg, cortisol) will be required to determine whether the risks to physical health go beyond the hypothetical.

In conclusion, we are among the first to provide evidence from a large cohort on the mental health impact of the COVID-19 pandemic on people in the UK. We provide early evidence that women, young people and individuals in recognised COVID-19 risk groups may be at particular risk. However, the strongest associations were with psychological characteristics such as worry about contracting COVID-19 and perceived loneliness. These findings, we suggest, indicate that robust public health measures, such as effective contact tracing, which reduce the public's concerns regarding risk of infection, could do much to ameliorate mental health difficulties.

Twitter Ru Jia @RJ_ruthj and Kavita Vedhara @kavitavedhara

Acknowledgements We would like to acknowledge the valuable contributions of our Patient andPublic Involvement Group in supporting the design of our recruitment strategy, contents of the survey and the communication of findings to study participants.

Contributors RJ: study design, coordination and management of recruitment, preparation, analysis and interpretation of data, preparation and review of final manuscript. KA: study design, coordination and management of recruitment, preparation, analysis and interpretation of data preparation and review of final manuscript. TC: study design, analysis and interpretation of data preparation and review of final manuscript. AM: study design, coordination and management of recruitment, preparation, analysis and interpretation of data and review of final manuscript. EB: study design, interpretation of data and review of final manuscript. CC: study design, analysis and interpretation of data, preparation and review of final manuscript. KV: research lead and overall guarantor for the article contributing to study design, coordination and management of recruitment, preparation, analysis and interpretation of data and preparation of manuscript. As corresponding author, $\mathrm{KV}$ had access to all the data in the study and had final responsibility for the decision to submit for publication.

Funding KA was supported by funding from the National Institute for Health Research (NIHR) School for Primary Care Research. The views expressed are those of the author(s) and not necessarily those of the NIHR, the NHS or the Department 
of Health. TC acknowledges the financial support of the Department of Health via the NIHR Specialist Biomedical Research Centre for Mental Health award to the South London and Maudsley NHS Foundation Trust and the Institute of Psychiatry at King's College London. The views expressed are those of the authors and not necessarily those of the National Health Service (NHS), the NIHR or the Department of Health and Social Care.

Competing interests None declared.

Patient consent for publication Not required.

Ethics approval Ethical approval was granted from the University of Nottingham Faculty of Medicine and Health Sciences (ref: 506-2003) and the NHS Health Research Authority (ref: 20/HRA/1858)

Provenance and peer review Not commissioned; externally peer reviewed.

Data availability statement Data are available upon reasonable request. Data will be deposited in the University of Nottingham data archive. Access to this dataset will be embargoed for a period of 12 months to permit planned analyses of the dataset. After that it may be shared with the consent of the Chief Investigator. Extra data is available by contacting kavita.vedhara@nottingham.ac.uk.

Open access This is an open access article distributed in accordance with the Creative Commons Attribution Non Commercial (CC BY-NC 4.0) license, which permits others to distribute, remix, adapt, build upon this work non-commercially, and license their derivative works on different terms, provided the original work is properly cited, appropriate credit is given, any changes made indicated, and the use is non-commercial. See: http://creativecommons.org/licenses/by-nc/4.0/.

\section{ORCID iDs}

Elizabeth Broadbent http://orcid.org/0000-0003-3626-9100

Kavita Vedhara http://orcid.org/0000-0002-9940-7534

\section{REFERENCES}

1 Holmes EA, O'Connor RC, Perry VH, et al. Multidisciplinary research priorities for the COVID-19 pandemic: a call for action for mental health science. Lancet Psychiatry 2020;7:547-60.

2 Candan SA, Elibol N, Abdullahi A. Consideration of prevention and management of long-term consequences of post-acute respiratory distress syndrome in patients with COVID-19. Physiother Theory Pract 2020;36:663-8.

3 Liu S, Yang L, Zhang C, et al. Online mental health services in China during the COVID-19 outbreak. Lancet Psychiatry 2020;7:e17-18.

4 Tian F, Li H, Tian S, et al. Psychological symptoms of ordinary Chinese citizens based on SCL-90 during the level I emergency response to COVID-19. Psychiatry Res 2020;288:112992.

5 Jeong H, Yim HW, Song Y-J, et al. Mental health status of people isolated due to middle East respiratory syndrome. Epidemiol Health 2016;38:e2016048-e48.

6 Chan SMS, Chiu FKH, Lam CWL, et al. Elderly suicide and the 2003 SARS epidemic in Hong Kong. Int J Geriatr Psychiatry 2006;21:113-8.

7 Williams SN, Armitage CJ, Tampe T, et al. Public perceptions and experiences of social distancing and social isolation during the COVID-19 pandemic: a UK-based focus group study. BMJ Open 2020;10:e039334.

8 Office for National Satistics. Coronavirus (COVID-19) related deaths by occupation, England and Wales: deaths registered up to and including 20 April 2020. Available: https://www.ons.gov.uk/peoplepo pulationandcommunity/healthandsocialcare/causesofdeath/bulletins/ coronaviruscovid19relateddeathsbyoccupationenglandandwales/ deathsregistereduptoandincluding20april2020 [Accessed 11 May 2020].

9 Zhou F, Yu T, Du R, et al. Clinical course and risk factors for mortality of adult inpatients with COVID-19 in Wuhan, China: a retrospective cohort study. Lancet 2020;395:1054-62.

10 Khunti K, Singh AK, Pareek M, et al. Is ethnicity linked to incidence or outcomes of covid-19? BMJ 2020;369:m1548.

11 Folkman S. Positive psychological states and coping with severe stress. Soc Sci Med 1997;45:1207-21.

12 Bults M, Beaujean DJ, de Zwart O, et al. Perceived risk, anxiety, and behavioural responses of the general public during the early phase of the influenza A ( $\mathrm{H} 1 \mathrm{~N} 1)$ pandemic in the Netherlands: results of three consecutive online surveys. BMC Public Health 2011;11:2.
13 Salkovskis PM, Rimes KA, Warwick HMC, et al. The health anxiety inventory: development and validation of scales for the measurement of health anxiety and hypochondriasis. Psychol Med 2002;32:843-53.

14 Gao J, Zheng P, Jia Y, et al. Mental health problems and social media exposure during COVID-19 outbreak. PLOS One 2020;15:e0231924.

15 Wang J, Mann F, Lloyd-Evans B, et al. Associations between loneliness and perceived social support and outcomes of mental health problems: a systematic review. BMC Psychiatry 2018;18:156.

16 Leigh-Hunt N, Bagguley D, Bash K, et al. An overview of systematic reviews on the public health consequences of social isolation and loneliness. Public Health 2017;152:157-71.

17 Pressman SD, Jenkins BN, Moskowitz JT. Positive affect and health: what do we know and where next should we go? Annu Rev Psychol 2019;70:627-50.

18 Larsen JT, Hershfield HE, Stastny BJ, et al. On the relationship between positive and negative affect: their correlation and their cooccurrence. Emotion 2017;17:323-36.

19 Dejonckheere E, Mestdagh M, Verdonck S, et al. The relation between positive and negative affect becomes more negative in response to personally relevant events. Emotion 2019:emo0000697.

20 Schotanus-Dijkstra M, Ten Have M, Lamers SMA, et al. The longitudinal relationship between flourishing mental health and incident mood, anxiety and substance use disorders. Eur J Public Health 2017;27:563-8.

21 Schotanus-Dijkstra M, Keyes CLM, de Graaf R, et al. Recovery from mood and anxiety disorders: the influence of positive mental health. $J$ Affect Disord 2019;252:107-13.

22 Kroenke K, Spitzer RL, Williams JBW, et al. The patient health questionnaire somatic, anxiety, and depressive symptom scales: a systematic review. Gen Hosp Psychiatry 2010;32:345-59.

23 Spitzer RL, Kroenke K, Williams JBW, et al. A brief measure for assessing generalized anxiety disorder: the GAD-7. Arch Intern Med 2006;166:1092-7.

24 Cohen S. Perceived stress in a probability sample of the United States. the social psychology of health. Thousand Oaks, CA, US: Sage Publications, Inc, 1988: 31-67.

25 Diener E, Wirtz D, Tov W, et al. New well-being measures: short scales to assess Flourishing and positive and negative feelings. Soc Indic Res 2010;97:143-56.

26 Lumley T, Diehr P, Emerson S, et al. The importance of the normality assumption in large public health data sets. Annu Rev Public Health 2002;23:151-69.

27 Kocalevent R-D, Hinz A, Brähler E. Standardization of the depression screener patient health questionnaire (PHQ-9) in the general population. Gen Hosp Psychiatry 2013;35:551-5.

28 Warttig SL, Forshaw MJ, South J, et al. New, normative, Englishsample data for the short form perceived stress scale (PSS-4). $J$ Health Psychol 2013;18:1617-28.

29 Löwe B, Decker O, Müller S, et al. Validation and standardization of the generalized anxiety disorder screener (GAD-7) in the general population. Med Care 2008;46:266-74.

30 Owen JE, Bantum Erin O'Carroll, Criswell K, et al. Representativeness of two sampling procedures for an Internet intervention targeting cancer-related distress: a comparison of convenience and registry samples. J Behav Med 2014;37:630-41.

31 NHS Digital. Mental health and wellbeing in England. adult psychiatric morbidity survey 2014 . Available: https://files.digital.nhs. uk/pdf/q/3/mental_health_and_wellbeing_in_england_full_report.pdf [Accessed 03 May 20].

32 Hidaka BH. Depression as a disease of modernity: explanations for increasing prevalence. J Affect Disord 2012;140:205-14.

33 Chabaud F, Benradia I, Bouet R, et al. Facteurs de risque sociodémographiques et troubles mentaux : modèle global et spécificités locales, d'après les résultats de l'enquête " santé mentale en population générale » dans 18 sites internationaux. L'Encéphale 2017;43:540-57.

34 March Network. The Covid-19 social study. Available: https://www. marchnetwork.org/research [Accessed 04 May 20].

35 Masi CM, Chen $\mathrm{H}-\mathrm{Y}$, Hawkley LC, et al. A meta-analysis of interventions to reduce loneliness. Pers Soc Psychol Rev 2011;15:219-66.

36 The British Psychological Society. 'We will have to live with the risk of Covid-19... but Psychology has much to say about that risk'. Available: https://thepsychologist.bps.org.uk/we-will-have-live-riskcovid-19-psychology-has-much-say-about-risk [Accessed 06 May 2020]. 